\title{
La imagen de Edison desde una crónica martiana
}

\author{
Edison's Profile from a Marti's Chronicle
}

\section{O perfil da Edison a partir de una Crônica de José Martí}

Yisel Bernardes-Martínez

Investigadora

Centro de Estudios Martianos

Cuba

Recibido: 25/9/2015

Aceptado. 20/7/2016

\section{Resumen}

La crónica que Martí dedica a Thomas Alva Edison, publicada en El Partido Liberal el 5 de febrero de $1890^{1}$ perteneciente a uno de los tomos de la Edición Crítica, en fase de investigación y cotejada en microfilme, nos permite apreciar la originalidad del científico y el hombre.

1 La crónica aparece publicada en El Partido Liberal, el 5 de febrero de 1890, pero sin firma, aunque por el estilo se considera indudablemente de Martí. Véase la crónica y las aclaraciones sobre el texto en Otras crónicas de Nueva York. José Martí con investigación, introducción e índice de cartas de Ernesto Mejía Sánchez, CEM, 1983, pp. 136147 y p. 258.

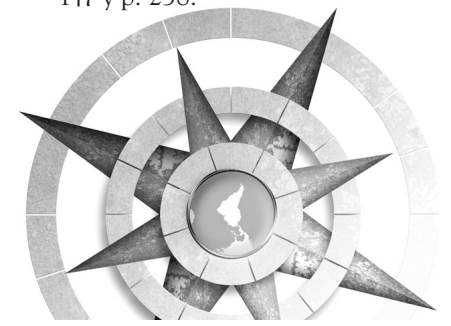

Al analizar la imagen que construye Martí de Edison, llama la atención la relación que establece el genial inventor entre sus creaciones, lo natural y el misterio, pues el hombre de ciencia tiene también visiones místicas y fantasías, de ahí que haya una vinculación entre Dios con la ciencia, así como entre la poesía y las ciencias, en especial las matemáticas. El presente artículo analiza estas relaciones.

Palabras clave: José Martí, Tomás Alva Edison, pensamiento latinoamericano, historia de las ideas, Temas de Nuestra América 


\begin{abstract}
The chronicle that Martí dedicated to Thomas Alva Edison lets us appreciate the originality of the man and the scientist. This chronicle was published in El Partido Liberal on February 5th, 1890, and included in one of the volumes of Edición Crítica [Critical Edition]-still under investigation and checked against microfilms. When analyzing the Edison's profile Martí outlined, what is striking is the relationship the great inventor established between his creations, nature and mystery, since the scientist also had mystical visions and fantasies; hence, there was a connection between God and science, as well as between poetry and sciences, especially mathematics. The present article analyses these relationships.
\end{abstract}

Keywords: José Martí, Thomas Alva Edison, Latin American Thought, history of ideas, Temas de Nuestra América.

\section{Resumo}

A crônica que Marti dedicou a Thomas Alva Edison foi publicado no El Partido Liberal em 5 de Fevereiro de 1890. O texto nos permite apreciar a originalidade do homem e cientista, a partir da análise da imagem de Edison a relação entre o grande inventor, suas criações, a natureza e o mistério é revelado. $\bigcirc$ grande cientista também tem visões místicas, com ligações entre Deus e ciência, poesia e ciência, especialmente matemática. Este artigo analisa essas relações.

Palavras chave: José Martí, Tomás Alva Edison, pensamento latino-americano, historia da ideas, Temas da Nossa America

En el texto en estudio se puede disfrutar a un hombre en el cual se mezcla el científico talentoso, batallador, con el hombre relajado, de buen humor, ameno y conversador. A través de símbolos, el escritor nos ofrece, de manera original, en un hombre, el valor de la inteligencia y su actitud ética. Asimismo, aprovecha un posicionamiento en dicha actitud para darnos lecciones desde la naturaleza: "Los pícaros parece que hieden. Se limpian las botas y usan brillantes en el plastrón, pero hieden..." (Martí, 1983: p. 136), nos afirma el Apóstol, para asegurarnos que en la inteligencia asociada con valores esenciales, se contiene el aroma de la verdadera vida.

Pero analicemos desde el inicio la crónica en que Martí le hace un homenaje a este gran hombre: "Desde que estuvo

6 Se publica en Otras crónicas de Nueva York [En lo sucesivo, OCNY. (N. de la E.)] 
Edison en París, se habla más de él. El hombre, misterioso y natural, admira tanto como el inventor." (1983: 136). La relación entre el misterio y lo natural se encuentra contenida en la personalidad del científico, porque lo misterioso necesariamente no es sinónimo de recargado y en la naturaleza hay mucho de mágico y misterioso. El hombre natural, despojado de toda pose, que hasta cuando bromea con cierta posición social, deja ver su autenticidad e irreverencia ante lo banal y artificial de la sociedad, resulta todo un misterio para la mayoría de los hombres que ignoran la capacidad de hallarse en el silencio de lo natural. Por eso, su manera de vivir, su modo de crear, admira tanto como los resultados gloriosos del inventor. A continuación nos dice Martí que "Vive con las manos en lo desconocido, y tiene visiones como las del místico Swedenborg y fantasías como las de Poe o de Quincey." (p. 136).

El inventor vive con osadía y emoción su existencia, pues busca hallar lo desconocido, su manera de existir es actuando, entrando en el universo de lo desconocido. Sus visiones, salidas de intuiciones, son místicas y fantasiosas pues en todo lo que hace ese hombre hay ciencia, filosofía y poesía. Se nutre del talento de escritores que admira y también de la creencia de un mundo invisible, su fantasía, que no es igual a irrealidad, sino creencia en un modo especial, resulta como el ideal de concebir para que la humanidad avance y viva mejor.

De ahí que tenga visiones tan originales como las del místico sueco Emanuel Swedenborg, quien nació en 1688 y fue científico, teólogo y filósofo. Hizo los planos de un avión, de un submarino, descubrió la función de las glándulas endocrinas, el funcionamiento del cerebro y el cerebelo y, a la edad de 56 años, se le ocurrió abandonar sus investigaciones científicas para hacer descubrir a los hombres una espiritualidad racional pues, según afirmaba, Cristo se le había revelado para cumplir la misión de reconducir la religión y la interpretación de las escrituras cristianas. Swedenborg, aunque distante en el tiempo de Edison, estuvo cerca desde el espíritu.

Martí también compara las fantasías de Edison con las de Poe y Quincey. El primero hizo que los mejores artistas utilizaran sus imaginativas obras como base para sus teorías estéticas. El hombre que revolucionó el cuento de terror y escribió algunos de los mejores poemas líricos del mundo, influyó en la capacidad imaginativa del inventor. El británico Thomas de Quincey, el escritor adicto al opio, rebelde, rompió con su familia tradicional, huyó y en un palacio vacío fue amparado por una prostituta angelical. Quincey, fue un 
periodista y escritor que con su fantasía tan original rompió con la lógica y el buen sentido burgués británico y buscó en las drogas un escape al aburrimiento de una inteligencia superdotada.

Por eso, no es de extrañar que Martí nos afirme refiriéndose a Edison que: "Para este físico, todo átomo tiene alma. Le preguntan por Dios, y dice que casi lo ha visto, casi puede probar la existencia de Dios con la química." (1983: p. 136)

Edison ve y siente el espíritu en todo, solo que concretiza para ganar en vigor. De ahí que establece su relación con la ciencia y Dios. Su manera de creer y respetar el mundo del espíritu es trabajando, desde lo desconocido que le fascina. A continuación el cronista destaca que "Tiene este mecánico, una poesía matemática y formidable.” (p. 136).

Recordemos a Martí cuando le escribía a María Mantilla, su niña, desde Cabo Haitiano, el 9 de abril de 1895 y señalaba que donde él veía poesía mayor era en los libros de ciencia, en la vida del mundo, en el orden del mundo, en el fondo del mar, en la verdad y música del árbol, y su fuerza y amores, en lo alto del cielo, con sus familias de estrellas, “- y en la unidad del universo, que encierra tantas cosas diferentes, y es todo uno, y reposa en la luz de la noche del trabajo productivo del día." (Martí, 1991: 218). Eso es lo que destaca el periodista del científico: el hombre que crea y piensa con elementos de ciencias también lo logra con poesía porque cree en el valor de la fantasía, del misterio y de los pasajes recónditos del alma.

Para Edison el hombre lleva en sí todos los dones de la naturaleza y el deber de cada persona es emplearlo al máximo, cuando observa a la naturaleza descubre los elementos de gradación como el silencio de los peces, el ruido que hace la bestia en la tierra y el canto del pájaro en el aire. Pero en su actuación confirma que el hombre lleva en sí toda la música del aire, el alboroto, la acción de la tierra, el poder y silencio del mar.

Ese es el poder del hombre, pues Edison no quiere saber de este dogma ni de aquél; sino de lo esencial de la fe en Dios que es la claridad que nos conduce. La creencia en la comunicación constante y benéfica con lo divino y con lo humano, la necesidad de creer en lo que se hace y se piensa, incluso, creer en el error con tal que se crea. ¡Eso sí, creer! para que emerja la sensibilidad humana, para que el hombre no oprima a sus inferiores y que no se viva para la mera bestialidad. Este Edison, que fuma sin parar, contiene la sabiduría humana, cuyos ingredientes esenciales son su talento y 
voluntad conjugados con la simpatía de la llaneza y la autoridad de la sensatez. Lo anterior se puede apreciar cuando

Un día, de sobremesa, rompe a hablar así, desde la nube de humo: "iQué gran cosa sería que el hombre pudiese mandar en sus átomos a voluntad, y que cada átomo fuese de quitar y poner! Así podría yo, por ejemplo, decir a mi átomo número 4,520 . Ve, y sé parte de una rosa por un poco de tiempo: y a cada uno de los átomos lo mandaría a que se hiciese parte de los minerales, de las plantas, de las sustancias todas. Luego, tocando un botón, los átomos volverían a mi cuerpo, con todo lo que hubieran aprendido, y yo sabría el misterio de la piedra, del gusano de luz y de la rosa. (Martí, 1983:136)

El científico, relajado, de buen humor, después de su sobremesa y disfrutando sus tabacos, habla de aspectos novedosos y hondos, como si se refiriera a temas cotidianos. Y es que él asume la cotidianidad de manera especial: en él encontramos una mezcla de voluntad para trabajar, un enorme potencial de creatividad y una armonía entre las fuerzas de tensión y relajación. Por esta razón, logra una existencia fructífera, entretenida, con ilusión hacia la propia vida. Pero siempre es un mundo interior construido por él, desde sus capacidades y voluntad.
En el misterio de la naturaleza que él quisiera conocer, brota cierto aliento poético. Esta forma original de verla lleva a interpretar las relaciones entre los organismos y con el entorno, relaciones no regidas por la competencia sino por el equilibrio en forma de redes complejas de interacciones que los comunican entre sí y con el ambiente. Por eso, Edison quisiera conocer las particularidades de cada elemento natural.

La fantasía de Edison parte de una razón constructiva. Cuando analizamos en su contenido simbólico algunos de los elementos de la naturaleza a los que hace referencia, podemos percatarnos de dicha lógica. Por ejemplo, la rosa en la poesía encarna todo lo que es superior y refinado; simboliza la imaginación, la cual precede al tránsito de inspiración a idea madura o fruto. Con este tropo se establece un paralelismo con el ser humano pues las rosas representan la juventud y la belleza y son símbolos del aspecto más noble y puro de la vida humana.

Pero Edison quiere embriagarse también con las sustancias de las plantas, de las piedras, del gusano. Este anhelo, aparentemente un tanto dislocado, de conocer profundamente los misterios de la naturaleza, se relaciona también con el hecho de que el hombre a través de los siglos le aportó un carácter simbólico a los elementos de la naturaleza. Por ejemplo, la piedra en su sentido 
humano puede ser vista como símbolo del ser, de la cohesión y la conformidad consigo mismo. Su dureza y duración impresionaron a los hombres quienes vieron en la piedra lo contrario de lo biológico, sometido a las leyes del cambio, la decrepitud y la muerte, pero también lo contrario al polvo, la arena y las piedrecillas, aspectos de la disgregación.

La piedra entera simbolizó la unidad y la fuerza; la piedra rota en muchos fragmentos, el desmembramiento, la disgregación psíquica, la enfermedad, la muerte y la derrota. Las piedras caídas del cielo explicaron el origen de la vida. En los volcanes, el aire se transformaba en fuego, este en agua y el agua en piedra. Por eso, la piedra constituye la primera solidificación del ritmo creador, la escultura del movimiento esencial, es la música petrificada de la creación. ${ }^{7}$

Como puede apreciarse, en la crónica el elemento visual es primordial y la imaginación del científico encuentra una instantánea analogía con la manera de pensar del cronista que lo admira. La realidad tiene para Martí y Edison una doble vertiente: el evidente dominio de la experiencia cotidiana y un orbe espi-

7 Véase Marius Schneider (1946) El origen musical de los animales-símbolos en la mitología y la escultura antiguas y La danza de espadas y la tarantela (1948) para abundar en la piedra como símbolo. ritual al que llama la realidad espiritual. Esta forma parte de un mundo ideal que van elaborando por medio de un lenguaje y accionar expresivos. En ambos, en el escritor y el científico, el idealismo adopta la sustancia del realismo. Martí al referirse a Edison se pregunta:

¿No es el hombre de las "tres mil" teorías sobre la luz incandescente? ¿No hizo viajar a decenas de hombres por las florestas vírgenes, para encontrar la fibra de la luz? Los átomos, para él, se condensan y coronan en el hombre, que representa la inteligencia total, "porque los átomos, todos, son inteligentes". ¿Sin inteligencia, producirían con sus conjuntos el color, la forma, el aroma? La vida es aroma. Lo que decae, hiede. Los pícaros parece que hieden. Se limpian las botas y usan brillantes en el plastrón, pero hieden. (1983:136)

Martí destaca, de manera sintética y comprensible para un público general, los méritos de Edison y hace hincapié en las teorías sobre la luz incandescente. La luz, que en el universo poético, entre otros significados, entraña una concepción positiva y optimista de la vida, inspirada por la decisión de consagrarse al perfeccionamiento y a la exaltación del género humano. 
Por otra parte, el cronista hace referencia a una de las ideas más originales y constructivas de Edison, al reafirmar el valor de la inteligencia y sus propiedades como el color, la forma, el aroma. Al hacer referencia al contenido de la inteligencia, Edison y Martí utilizan, el aroma como símbolo de vida, relacionada con los momentos de esplendor de la existencia humana, los valores humanos y las conductas ante la vida. De esta manera estamos hablando de un aroma, salido de las entrañas, en medio del apogeo de las mejores fuerzas para crear y trabajar; y, tal parece que la sanidad mental hace que salga del hombre un aroma de vida -agradable-- porque, en contraste, la picardía, en que se resume en este contexto todos los antivalores al decir de Edison, parece que hiede aunque se limpien las botas y vistan con brillantes. Para el inventor, la decadencia está relacionada con el hedor.

A continuación, ambos hombres nos aclaran que, aunque el hombre como especie viva representa la inteligencia total, esta no es un don pasivo pues:

La inteligencia está en nosotros; pero no nos viene de nosotros mismos. La materia no es inerte, ni recibe su fuerza de afuera.-Y estas son las cosas de que habla de sobremesa el inventor del tasímetro, envuelta la cara pálida en la nube de humo. (p. 136)
Cuando leemos la crónica apreciamos el contenido de vida de Edison, cómo disfruta queriendo descifrar el misterio de la propia existencia habituándose al trabajo, al orden y belleza. Con el entretenimiento de los dibujos concibe sus inventos casi como jugando y eleva el espíritu con la música, lo ennoblece desde la raíz, con los tonos sentidos compuestos para el arte; porque conoce él de la verdadera grandeza humana y de cómo el hombre es noble, y tiende a lo mejor y el que conoce lo bello, y la moral que viene de él, no puede vivir luego sin moral y belleza.

Más adelante, Martí nos presenta el modo original de trabajar y crear del científico, porque Edison asume como sentido de su vida y divertimento la creación incesante y el trabajo, esto lo hace de manera permanente, con emoción, de manera fluida:

Porque Edison fuma sin cesar: fuma quince, veinte tabacos al día: cuando no fuma, masca: recostado en una silla, con los pies sobre el respaldo de otra, a la nuca el sombrero de pelo, por el suelo los faldones de la levita negra, cambiándole de color los ojos chispeantes, va dibujando con los mascullones de tabaco en la pared la máquina que inventa.(p. 136) 
De manera sintética, Martí nos revela la personalidad de Edison. El hombre irreverente y original salta a la vista, no hay dogmas en el inventor que tiene los ojos chispeantes de la permanente emoción que produce crear. También nos ofrece el modo de trabajar y crear del inventor. Así asume su existencia Edison, pues en la posesión de sus valores legítimos, en el apogeo de sus fuerzas y capacidades, este hombre, que fuma, se sienta reposadamente y como quiere, vestido con su sombrero y una larga levita negra, dibuja con los mascullones de su tabaco, la máquina que tiene en mente. Se coloca el inventor por siempre en la línea divisoria de la experiencia meramente cotidiana y lo trascendente. En esos ojos que brillan, persiste un anhelo de ir hacia delante en complicidad y lealtad con el futuro, y el desespero desenfrenado de inspiración, liberan por completo al inventor de las presiones temporales y hace que el hombre liberado por su capacidad de trabajar, construya su propia cotidianidad creadora y entusiasta que lo abalanza hacia su destino. "De pronto, echa por tierra las sillas, y se sienta, sin quitarse el sombrero, a tocar el órgano, en las horas profundas de la noche. Se levanta del órgano, a anotar, con dibujos, la máquina en que piensa." (p. 136).

Hay una permanente actividad del espíritu en él. Y la música le sirve de inspiración para obtener sus invencio- nes. Por otra parte, llama la atención su capacidad para concentrarse, pues todo el tiempo, placenteramente, está pensando en su trabajo como sentido que colma su existencia superior.

En la actitud de Edison se aprecia la creencia martiana de que por el arte se penetra al aliento de la vida misma como esencia que puede llegar hasta lo maravilloso y creador. Y en las horas profundas de la noche, trabaja, acompañado de la música. Porque en la noche el hombre puede encontrarse mejor, pues no hay interrupciones. De día, nuestros movimientos son más bruscos, y hasta para el creador concentrado hay aturdimiento. Por tanto, al tocar el órgano como mero placer que busca la inspiración, lo primero que hace Edison es bajar el ritmo para, poco a poco, escuchar lo que la mente le dicta y anota con dibujos la máquina en que piensa, en ese momento de silencio y encuentro consigo:

Cientos, miles de máquinas. Los cálculos los hace pronto, por métodos suyos. Cuando un novelista lo va a ver, le saca el libro de los dibujos: "¡Aquí tiene mi novela!" Y le deja el libro en las manos: se le ha ocurrido una idea, ha recordado la página de un libro, y va a su cuarto de leer, donde mesas, sillas, alfombra, están llenas de libros abiertos. Salta de 
uno a otro. Lee en todos a la vez. Estudia un asunto, y manda comprar cuanto hay escrito sobre lo que estudia. Resuelve, y olvida. (pp. 136-137)

Su agilidad para inventar, la rapidez con que realiza los cálculos, su propio método de trabajo y el proceso de investigación que lleva a cabo al relacionar lo leído, nos ofrece una imagen de permanente movimiento.

La acumulación de pensamiento que parece confusión, cuando no es más que luminosa brevedad, esos saltos de un libro a otro, y como la mente está entrenada, pensando todo el día en sus proyectos, encuentra pronto la información que necesita. Se la pasa estudiando, pero no se aferra a lo aprendido. Después que estudia un asunto, teniendo en cuenta todos los referentes bibliográficos, resuelve el problema científico y olvida. Porque la principal y mejor capacidad del cerebro es olvidar, no almacenar, pues se corre el riesgo de dogmatizar y llenar de etiquetas y convenciones los razonamientos. El acto de olvidar lo ya resuelto, hace que el inventor vaya hacia adelante y deje espacios frescos para su proceso de creación. Su tiempo lo emplea con intensidad y novedad, de él brota un dinamismo interior que siempre lo acompaña.
Cuando el cronista nos regala una imagen del trabajador, podemos disfrutar el trayecto, el contenido sustancial de la cotidianidad de Edison tanto o más que sus logros finales, porque con esa imagen elocuente en que nos pone a Edison a caminar rápido, a sentarse luego irreverentemente, a saltar de un libro a otro, a tocar el órgano, a investigar, a crear con la ayuda de su tabaco, nos da una lección a gritos de cómo debe ser nuestro bregar.

También en esta grata imagen que nos regala el cronista, está contenido el precepto martiano de que el éxito de los hombres no se mide por su éxito inmediato, sino por su éxito definitivo. Tampoco se mide por el dinero que acumularon, sino por el resultado de sus obras.

Pero Martí también nos completa la imagen de Edison, con el hombre amigo, entusiasta, que jamás pierde su condición de muchacho que aprendió a vivir desde abajo:

Si algún amigo entra a hora propicia, de levita y sombrero alto se pone a picar chistes, a canturrear, a hablar yankee por lo fino: o a bailar el zapateo, sombrero en mano y faldones por el aire, como cuando lo fue a ver Sarah Bernhardt. ¡Siempre 
el muchacho errante, siempre el telegrafista aprendiz, siempre el que aprendió la vida en lo duro! (p. 137)

Se disfruta en este fragmento su alegría para vivir verdaderamente, creando y fantaseando como un niño, sin olvidar sus orígenes humildes que se rebelan en nunca conformarse con sobrevivir. El hombre que no juega con su talento, pues se impone una disciplina esencial del tiempo y de todo, porque el amigo debe llegar en hora propicia, espontáneamente bromea, canturrea, baila cuando llegan sus amigos.

Y Martí resalta en Edison su capacidad para no olvidar su esencia humana y mantener dentro de sí al "muchacho errante", al "telegrafista aprendiz", que aprendió la vida a través de un camino propio. En el aspecto simbólico, una propiedad constante del camino construido con esfuerzo es su dificultad. Recordemos que el camino como símbolo en la literatura nos plantea, entre otras cuestiones, el emprendimiento conscientemente del hombre que está construido de acuerdo con una línea de dificultad y peligro siempre crecientes, por eso la superación del camino es una hazaña.
El término del camino es el objetivo del movimiento, donde se encuentran los valores sagrados superiores del mundo, o bien una dificultad (peligro, amenaza), que, luego de ser superada o eliminada, permite el acceso a estos valores. Esta imagen dinámica del camino, ligada a un riesgo máximo, responde al carácter del mundo concebido por la conciencia mitopoética por lo que tiene significación y valor lo que está vinculado a un esfuerzo extremo, a una situación, en la cual tiene lugar el proceso de formación del hombre. Sin embargo, nos dice Martí que Edison:

Se las da ahora de prohombre, desde que vino de París; hace que lo retraten en su biblioteca, de gorro y bata de señor; se sienta, de mucha casaca, en el banquete de los descendientes, de holandeses, porque él también desciende de ellos, y la nobleza lo quiere ir levantando como persona nacional: pero de los ojos inquisidores no se le cae nunca la burla: ¿acaso ven los hombres lo que él ve? ¿qué saben esos, que peroran y que beben? ¡la hora de fumar es la que en los banquetes le place a Edison! Del tabaco negro, negro como la sombra, saca a bocanadas el humo azul. (p. 137) 
Edison asume las poses sociales con un tono burlón que se revela en los ojos inquisidores. El hombre que ha trabajado duro y se ha hecho a sí propio en la pobreza, desestima a los otros que descienden de la nobleza y solo hablan, beben, comen y andan de fiesta en fiesta, de banquete en banquete. Él sigue la rima y se deja retratar en la biblioteca y se sienta muy bien vestido con estos en los banquetes, pero sabe bien que la hora de fumar es el mejor momento de estos eventos sociales que él vive y disfruta con burla, manteniendo así, cierta distancia para no amenazar sus esencias humanas. Porque el hombre trabajador conoce muy bien que juzgar, hablar en demasía no es nada, que solo la acción nos precipita en el acto y otorga sentido a nuestra existencia.

El inventor es un hombre que posee estimación propia y todo aquel que ha transitado por un camino de sacrificio, esfuerzo y trabajo se burla y escamotea la alta sociedad, nacida de las herencias o de cierto destino en donde la picardía y la trampa lo acompañan. "¿acaso ven los hombres lo que él ve?" Se interroga Martí, para sugerirnos que Edison, con su sola presencia y sus valores reniega de los hombres que trabajan para tener más que el vecino, para cultivar lo grosero y feroz del hombre. Porque Edison resulta un ejemplo de cómo hacer tanto y vivir a poco costo, en albedrío individual, y con tiempo y gusto para las cosas del corazón y de la mente sin contrariar la naturaleza individual, y aun los defectos inevitables, y por tanto necesarios, del carácter del hombre. La imagen del científico logra completarse mediante los comentarios de sus amigos y con saltos del pasado al presente y viceversa.

Sus amigos hablan de su grandeza en las réplicas; de sus juicios breves y originales sobre los hombres; de cuando fue por primer vez a Washington, a pedir privilegio de invención para un aparato de marcar sin demora en los Congresos los síes y los nóes: de cuando lo despidió por celos el jefe de su oficina, y entró en San Luis, en una mañana de nieve, con el gabán de dril con que venía del Sur: de cuando llegó de telegrafista a Boston, se sentó a recibir mensajes, y cansó al empleado más hábil del telégrafo de Nueva York: de la celeridad con que concibe, el orden con que trabaja, y la infalibilidad con que calcula. (p. 137)

Su manera de expresarse, su comportamiento osado, siempre joven, prueba el hábito de pensar en alta voz, y de tener al aire libre las ideas, para irlo poniendo, de peldaño en peldaño, porque el hombre que vale por sí y se construye no tiene que salir por el mundo alquilando el lomo o devorando semejantes. Trabajar en lo verdadero, y decir sin 
miedo lo que se piensa: he ahí las dos raíces que conforman la personalidad de Edison.

Sin embargo, no fue tarea fácil hacerse valer en su oficio de inventor, pues vivió años muy duros en que trabajar en sus creaciones se hacía muy difícil. Por otra parte, el menor de siete hermanos había nacido con una salud precaria y alrededor de los doce años perdió la audición. Se puso de suerte cuando en 1862 Edison rescató a un niño de tres años de una pista en la cual un furgón estaba a punto de rodar y el padre, agradecido, le enseñó telegrafía. En ese invierno, tomó un trabajo como operador de telégrafo, y alternaba con su oficio de sobrevivencia la realización de sus experimentos científicos. Entre 1863 y 1867 Edison emigró de ciudad en ciudad para trabajar como telegrafista en lugares que estuvieran disponibles. En 1868 se trasladó a la ciudad de Boston donde trabajó en la oficina de Western Union, ahí tuvo la oportunidad de trabajar más tiempo en sus inventos. Pero ya en enero de 1869 renunció a su trabajo como telegrafista para dedicarse a tiempo completo a sus inventos y en junio de aquel mismo año, tuvo su primer invento para obtener una patente. Edison inventó un registrador de votos eléctricos, pero molesto por la renuencia de los políticos de utilizar la máquina, decidió que en el futuro no debía perder el tiempo inventando cosas que nadie quería.

De todo lo anterior nos habla también Martí, solo que a modo de síntesis, de las vicisitudes que vivió el inventor y de cómo con notable rapidez se sobrepuso y venció a la adversidad. Tal parece que todo lo vivido desde lo humano, le aportó "la celeridad con que concibe, el orden con que trabaja, y la infalibilidad con que calcula.” Por eso jamás pierde tiempo en banalidades, y busca el aislamiento necesario para crear, sin negar el valor de la amistad, a ella le dedica su hora propicia, pero el trabajo necesita de espacios alejados del ruido y el aturdimiento de la vida cotidiana. Entonces Martí al darnos su itinerario, nos comenta:

No le den "sociedades ni músicas", ni le traigan de "esos conversadores asesinos" a quitarle el tiempo: el día es claro, pero es más clara la noche: encaramado en la banqueta, o arrellanado en el sofá a la turca, es su placer mayor ver asomar al alba, como si la hubiera citado a duelo, y aguardase, en una hora de descuido, a arrebatarle el secreto de su luz. ¡Y si hay gusto de rey, luego de una buena noche de trabajo, en ver salir el sol! A las siete tocan a la puerta, y el inventor se echa famélico sobre el almuerzo: tira el sombrero por el aire: 
se frota contento las manos. ¡Ahora, desde que es persona de París, y anda en comidas de holandeses, ya no pasa tantas noches en vela como antes! (p. 137).

El científico tuvo que hacer una especie de decantación social para el científico haber esos aportes a la humanidad; en algún momento precisó negarse asistir a eventos sociales, fiestas que le quitaran concentración, pues la soledad del creador es esencial, sin ella se pierde el talento y la voluntad. Por otro lado, llama la atención el valor que le da a la noche para trabajar, al punto que la ve clara, pues es en esas horas en que se anula la distinción entre los seres humanos y casi todos están de reposo. Él, encaramado en la banqueta, o arrellanado en el sofá, puede crear y luego de toda una noche de trabajo puede también disfrutar del alba y sorprenderse con admirar su luz inicial. Hay poesía en este hombre, más bien yace el aliento poético de la naturaleza, porque ve como gusto de rey, luego de intensa labor nocturna, ver salir el sol, pues devoto de la fértil naturaleza, Edison aprecia en la energía del sol físico una intensidad fascinante que se merece admirar después de haber trabajado durante la noche.

Recordemos también en el acto de disfrutar el sol, que nuestra especie se originó en las zonas húmedas del África, al borde de los desiertos y siempre fue para nosotros un sentimiento de paz y de alivio ver los reflejos del sol sobre una corriente del agua, que nos diera la certeza de tenerlo allí, disponible para nosotros y para nuestra gente. Por otra parte, además de estas explicaciones racionales, se encuentran nuestras vivencias, pues en las sociedades, la vuelta a la naturaleza requiere de un esfuerzo para salir del molde que tenemos impuesto, y he ahí el esfuerzo intencionado que hace el científico para nutrir sus creaciones de esa savia de la naturaleza.

Porque en el apego al sol, también hallamos nuestras raíces primigenias. Por ejemplo, normalmente sonreímos los días soleados y nos invade un cansancio en los huesos cuando llueve. Quizás sería bueno preguntarnos ¿Por qué nos incomoda la lluvia, como a los demás primates? ¿Lo arrastramos desde los tiempos en que temíamos que la lluvia apagara nuestros fuegos y nos dejara a merced de las fieras? ¿O aún tenemos el temor de que la crecida del río se lleve nuestro precario hábitat? Lo cierto es que el sol es un premio, y así lo asume el inventor, que aprecia ese privilegio de verlo nacer con tal sensibilidad.

Después de una noche intensa de creación, Edison está contento, entusiasmado. Almuerza a las 7 a.m., sus hábitos son propios, se alimenta con el 
sentimiento feliz de quien ha cumplido con su deber y lo expresa con espontaneidad singular: como un niño tira el sombrero por el aire, se frota las manos, los movimientos corporales revelan la autenticidad del trabajador que no ha perdido la frescura de la niñez. Sin embargo, después de mucho trabajo durante largos años, llega el tiempo en que el hombre triunfador y glorioso, como ser humano que es, disfrute de comidas holandesas, y por tanto, debido al ajetreo social pierda un poco de concentración y ya no pase tantas noches en vela como antes.

A veces, después de almorzar, lee un libro de filósofo o de poeta. Los poetas de la esfinge son los que lee él: Emerson, el adivinador: Whitman, el verdadero: ¿no fue Emerson el que dijo, cuarenta años antes del fonógrafo, que ya vendría "quien organizase de los ecos?" Lee poetas ahora Edison, de cuando en cuando, de esos que ven con ojos nuevos, y escriben música extraña y poco oída, -como la que oyó él cuando su primer prueba en el fonógrafo. ¡Entonces no leía poetas Edison, ni sabía de Alutedon! (pp. 137-138)

Retoma Martí la idea de que después de almorzar, Edison lee algún libro de filósofo o de poeta. El trabajo es continuo y en esas horas en que ya el rendi- miento no es tan alto, se puede emplear el tiempo leyendo, nutriéndose de varias fuentes para realizar después en el acto de creación, posibles inferencias, asociaciones, pero eso se logra solo activando continuamente el cerebro con la lectura.

Edison no lee a cualquier poeta. Lee a Emerson, a quien Martí admiró muchísimo y en quien vio tantos puntos de contactos con él. Emerson es el poeta y filósofo de la naturaleza, el hombre que creyó en el poder del mundo invisible y adivinaba todos los movimientos del espíritu. También lee a Walt Whitman, el irreverente, de hablar cotidiano, sincero y que se cantó a sí mismo.

El cronista enfatiza en la capacidad de superación de Edison, porque cuando empezó a realizar sus inventos, casi de manera muy empírica y sin ningún recurso material, no leía poetas que ven con ojos nuevos y logran avizorar los inventos científicos del futuro como hizo Emerson cuando se refirió cuarenta años antes al fonógrafo. También lee libros que desarrollen la imaginación como Helionda, o Aventuras en el sol, publicado en 1855 en el cual Alutedon escolta a Benedict, personaje principal a su nueva residencia que se encuentra cerca del sol, donde habitan seres de gran sabiduría y belleza. Estas lecturas las realiza Edison desde hace un tiempo; para trabajar mejor, inspirándose 
en escritores, poetas, filósofos. El niño que a los doce años perdió la audición, ha crecido no solo en años, sino humanamente. La pérdida de esa capacidad y otras adversidades le sirvieron para prepararse mejor, pues la falta de audición le propició una mayor concentración en sus tareas investigativas, aunque influyó también en su carácter tímido que después hubo de superar, pues se volvió solitario a partir de ese momento.

En otro fragmento se recrea Martí en el invento del telégrafo:

Trabajaba de telegrafista; inventó un aparato para repetir, por las marcas del papel, los golpes del receptor, pensaba ya en el telégrafo, y en las vibraciones del sonido: pues "ipor qué, si las marcas del papel vuelven a hacer sonar el martillo del receptor, no han de quedar recogidas, y de sonar otra vez, las vibraciones del diafragma?". Anhelante, con un compañero descreído, armó un instrumento rudo y habló sobre una tira del papel: “¡Hallo!” dijo: ¡y repitió el saludo, como si viniera de muy lejos, la hoja de papel! A su mecánico se fue enseguida Edison con su dibujo de la máquina de hablar. Cuatro pesos le puso de precio, y se burló el mecánico de él. Edison acababa de contar la primera prueba, estaban él, el compañero Batchelor ${ }^{8}$ y el mecánico Kruesi. ${ }^{9}$ Un barril de manzanas aportó Batchelor "a que no andaba la cosa”. ¡Se reía el mecánico! Puso Edison en la máquina una hoja de lata, y habló sobre ella. ¡Se reía el mecánico! Volvió Edison a poner la hoja de lata, a que repitiese los sonidos. Echó a andar: iy no se rió, el mecánico! Palideció y dio un paso atrás. "También yo me asusté", dice Edison: "también yo me asusté un poco". Y Batchelor, perdió el barril de manzanas." (Martí: 1983: 138)

De manera coloquial, Martí nos expone cómo Edison inventa el telégrafo y lo pone a prueba ante sus compañeros. Esta acción trascendental, en la que reluce más bien el genio de la perseverancia, la realiza entre la tensión de probar su descubrimiento y el sentido del humor necesario para afrontar con osadía el miedo a lo desconocido y al posible fracaso. Después de años de trabajo como telegrafista, Edison hace su gran aporte a su oficio y a la humanidad.

Y para resaltar el esfuerzo sostenido del inventor para llegar a estos logros, Martí retoma los orígenes del científico:

8 "Batchelor", se refiere a Charles W. Batchelor. 9 John Kruesi. 
Aquel inventor, no había ido más que dos meses a la escuela. El padre vive y se anda hoy mismo diez millas diarias, con sus ochenta y cuatro años: pero era hombre de más fuerzas que medios. La madre era maestra, y le enseñó en la casa cuanto sabía. A los doce años, estaba Edison leyendo los Principios de Newton. A los doce años, "Madre", dijo, "soy un bushel de trigo: peso ochenta libras:" y se fue por el mundo, como un bushel de trigo. A qué? A lo primero en que se pudiese trabajar!: A vender diarios en el ferrocarril. (1983: pp. 138-139).

Como le ocurrió a muchos genios, Edison fue un mal estudiante en sus inicios. En una ocasión un maestro lo llamó cerebro podrido y su madre furiosa lo sacó de la escuela para ella misma enseñarle en la casa. Con ella tuvo una especial identificación, muchos años después afirmaría con orgullo que su madre estuvo siempre tan segura sobre él, que desde niño había sentido que ella era alguien por quién vivir y a quien valía la pena no defraudar.

\section{En 1859 Edison comenzó a trabajar} vendiendo periódicos y caramelos en el ferrocarril Grand Trunk en Detroit. En el vagón de equipajes creó un laboratorio para sus experimentos de química y una imprenta donde creó el Grand Trunk Herald, el primer periódico publi- cado en un tren. Desde temprana edad se fascinó por las cuestiones relacionadas con la mecánica y los experimentos químicos, así, se fue adentrando en ese mundo, a la par que trabajaba en lo que hubiera para ganarse la vida. Su camino fue intencionalmente complejo, parecido al de la historia mitológica de Teseo y Ariadna con su hilo de guía. Martí también se refiere al proceso que vivió Edison en el período cuando inventó el fonógrafo:

De ahí subió a "caballero de la llave", como se llamaban los telegrafistas. Noches enteras pasaba con un compañero, sirviendo de balde el puesto de un operario que dormía largo la cerveza. Años tardó, practicando e inventando. Imaginó un aparato; con dos registros de Morse y una taza de papel, para recibir de prisa y repetir despacio. De ahí paso a paso, llegó "por deducción lógica”, por la idea de las marcas del papel que daban el sonido, a la invención del repetidor automático, que ahorraba los operarios y yerros de la transmisión en cada oficina -llegó a la invención del fonógrafo. Hoy, de privilegios originales, tiene lleno un libro. (1983: 139)

Como puede apreciarse, Martí se entusiasma aún más con este hombre a quien admira y que, de alguna manera, se ve en 
él, cuando habla del invento del fonógrafo. No sin antes, en un solo fragmento sintetizar los apuros que pasó el científico. Llama la atención la perseverancia de Edison, que nunca usó sus intentos fallidos en cada uno de sus inventos como indicativo de su autoestima. Él utilizó los aparentes fracasos como experiencias productivas que lo llevaban a etapas superiores, y estos le sirvieron de incentivo al trabajo y a la exploración. Edison logró enfrentarse y vencer el miedo a lo desconocido mediante la osadía de probar siempre nuevas experiencias, el rechazo a la rigidez y a los prejuicios.

El científico trató de mantener la mente encendida, y al sentarse en la silla, se sentaba como en un potro. En las noches que pasaba en vela mantenía la cabeza alta con las ideas que chispean, buscando en la soledad nocturna la inspiración para que el fonógrafo recibiera algún día la palabra impaciente.

Recordemos que fue en 1876, cuando se creó el fonógrafo, el primer aparato capaz de reproducir sonido. Cuando Thomas Alva Edison anunció la invención de su primer fonógrafo, la primera pieza interpretada fue Mary had a littlelamb, el 21 de noviembre de 1877. Mostró el dispositivo por primera vez el 29 de noviembre de de aquel año y lo patentó el 19 de febrero de 1878 .
El fonógrafo reproduce el sonido, vierte al papel la frase vigorosa y fresca, la idea sale como se la concibe. Por otra parte, otra ventaja del fonógrafo consiste en borrar lo escrito y, a su vez, queda el rollo como nuevo.

Entonces, concluye Martí este homenaje al hombre creador y natural como él mismo fue, expresando:

¿Qué no ha inventado él? Desde los alambres de seis mensajes a la vez, desde los aparatos de telegrafía privada, ${ }^{10}$ desde el motógrafo del teléfono, hasta la subdivisión de la luz eléctrica, que los expertos ingleses habían declarado "imposible" ante la Cámara de los Comunes. Y cuando volvía de Francia, notó que no tenían los marinos modo seguro de tomar el sol en días nublados, calculó unas pocas horas, e inventó un aparato para tomar el sol, haya o no nubes. Y tiene palacio, riqueza, procesos, fama, mujer, y aquel inefable honor con que se empieza a ver el hombre cuando se enorgullece de él su patria. ${ }^{11}$ Pero deja su alcoba tranquila, para ir a oír ansioso a media noche la voz que lo llama, la voz que en La Obra de Zola llama al pobre Claudio. (pp. 139-140)

\footnotetext{
10 Se añade coma.

11 Se añade punto y seguido.
} 
Sus inventos, sus aportes científicos a la humanidad son el resultado de una larga técnica de aprendizaje. Como un real esfuerzo por crear un paralelismo entre su crecimiento humano con su actividad científica, pues Edison, junto con el cultivo de su talento y voluntad logró educar su alma y su espíritu, para así establecer una armoniosa correspondencia entre los sentimientos, constituyente esencial de la moral y su intelecto, cuya esencia es la razón para permitirle un dominio y dirección adecuados del mundo real y una participación perfecta en las jerarquías del universo.

Por otra parte, en la crónica se siente cómo el hombre también prestigia a su patria y esta le rinde honores, recordándonos así un fragmento en que Martí afirma que "...todo hombre está obligado a honrar con su vida privada, tanto como con la pública, a la patria." (1991: 55) El hombre, que desestimó la vida hipócrita, falsa y tuvo el valor de asumir sus propios códigos, hermoseó con la virtud del trabajo y venció sus límites; vivió el realismo pleno y verdadero, que es útil y encanta, ese apegado a la na- turaleza y a la creación. Por eso, ahora que tiene palacio, riqueza, fama, mujer y honor, deja atrás su alcoba tranquila como símbolo de lo conquistado para ansioso, de noche, escuchar la voz interior que lo llama de nuevo a la creación incesante, a la angustia y emoción de emprender nuevos caminos y dejar atrás lo ya vencido para afrontar otros misterios. Esa voz, que en La Obra, representa las luchas del pintor Claude Lantier por pintar una gran obra que refleje su talento y genio y ese afán le cuesta la vida, pues deprimido se suicida, y esa es la voz desesperada que escucha Edison, la que llama a la creación, la que te lleva al misterio de lo desconocido para que no se inmovilice el genio y prosiga su camino, a veces costoso, pero fascinante.

\section{Referencias bibliográficas}

Martí, J. (1983). Edison. Otras crónicas de Nueva York. La Habana: CEM. . (1991). Carta a María Mantilla. Obras completas. Tomo 20. La Habana: CEM. 